\title{
Differential activation energy and NBO interaction approaches to torquoselectivity and its dependence on the conformational profile of the substituent
}

\author{
Veejendra K. Yadav* \\ Department of Chemistry, Indian Institute of Technology Kanpur, Kanpur 208016, India \\ vijendra@iitk.ac.in
}

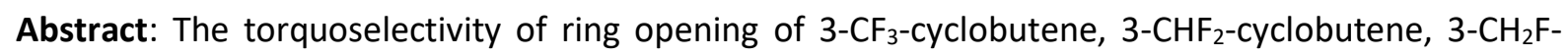
cyclobutene, 3- $\mathrm{CF}_{3}$-oxetene and perfluoro-3- $\mathrm{CH}_{3}-\mathrm{cyclobutene}$ have been studied at the MP2/cc-pVTZ level of theory and the results analysed by using the differential activation energy approach and also differential NBO interactions of the breaking ring bond with the substituent bonds. The outward or inward opening that has lower activation energy in the differential activation energy approach or larger interaction in the differential NBO interaction approach constitutes the preferred mode. The predictions from the two approaches are found to be largely contradicting each other, specifically when the substituent is electron-deficient. The $\mathrm{CHF}_{2}$ and $\mathrm{CH}_{2} \mathrm{~F}$ substituents on cyclobutene and oxetene can adopt primarily three distinct conformations with respect to the cleaving ring bond. It has been discovered that each conformer exhibits a distinct level of torquoselectivity and some may even contribute to the overall selectivity substantially. The conformational profile of the substituent, therefore, is recommended to be taken into consideration in any serious treatment of the subject. The experimental torquoselectivity, if otherwise, is a likely consequence of secondary reactions such as equilibration through reaction reversal while honouring the relative stabilities of ring opened species.

Keywords: torquoselectivity, 3-fluoromethylcyclobutenes, 2-fluoromethyloxetenes, 3methylperfluorocyclobutene, differential activation energy, differential NBO interaction, conformational effects

\section{Introduction}

The ring opening of cyclobutene proceeds in conrotatory fashion under thermal conditions to form 1,3-butadiene. ${ }^{1}$ The outward $(\mathbf{1} \rightarrow \mathbf{2})$ and inward $(\mathbf{3} \rightarrow \mathbf{4})$ rotations of, respectively, electron-rich and electron-deficient substituents are controlled by the phenomenon called torquoselectivity. It is typically predicted by estimating the transition structure barriers and the lower barrier pathway constitutes the preferred mode of opening. ${ }^{2}$ 


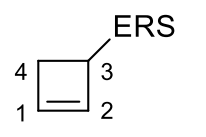

1

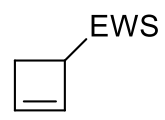

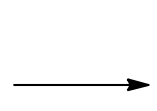

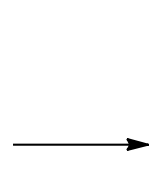

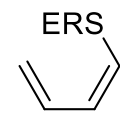

2

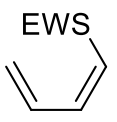

4

ERS $=$ Electron-Rich Substituent

EWS = Electron-Withdrawing Substituent

In 2001, Murakami and co-workers observed 83:17 kinetic distribution of the inward and outward opened products on heating 1-octyl-3-dimethylphenylsilylcyclobutene 5 at $140{ }^{\circ} \mathrm{C}$ in $m$-xylene for 1 hour. ${ }^{3}$ Likewise, the reaction of 1-dimethylphenylmethy-3-trimethysilylcyclobutene 8 at $140{ }^{\circ} \mathrm{C}$ in $\mathrm{m}$ xylene for 9 hours generated a 69:31 mixture of the inward and outward opened products, respectively. The preference for inward rotation of the silyl substituent was ascribed to a favorable overlap of the low lying $\sigma^{*}$ orbitals of the silyl substituent with the occupied $\sigma_{\text {сзс4 }}$ orbital of the breaking bond in the corresponding transition state (TS) structure. The differential activation energy approach predicts the inward opening of 3-trimethylsilylcyclobutene favored over outward opening by $2.0 \mathrm{kcal} / \mathrm{mol}$ at M06-2X/6-31G(d) level of theory. ${ }^{4}$ The inward and outward opening reactions of 3trimethylsilylcyclobutene are exergonic by, respectively, 6.7 and $9.2 \mathrm{kcal} / \mathrm{mol}$. The interaction $\sigma_{\mathrm{c} 344} \rightarrow$ $\sigma^{*}{ }_{\text {c-si }}$ was estimated at $11.3 \mathrm{kcal} / \mathrm{mol}$ in the inward TS structure as compared to only $5.0 \mathrm{kcal} / \mathrm{mol}$ in the outward TS structure.
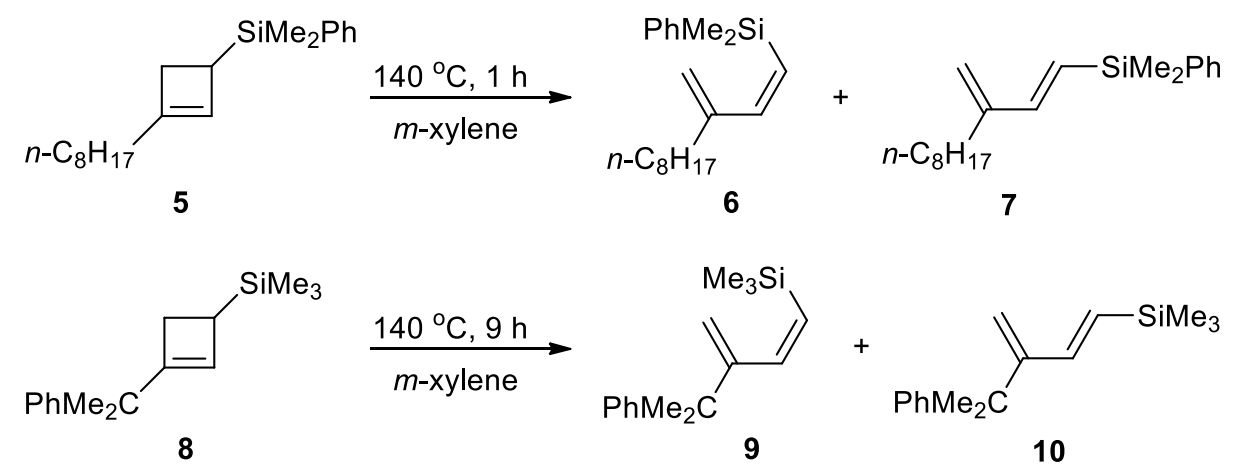

In 2003, Houk observed that the filled orbital of a donor substituent experienced closed-shell repulsion upon inward rotation and, therefore, it preferred to rotate outward. In contrast, a vacant acceptor orbital on the substituent was predicted for inward rotation to maximize orbital interaction between the filled orbital of the breaking bond and the vacant orbital of the substituent in the TS structure. ${ }^{5}$ Orbital interaction, thus, was indicated to be responsible for control on TS structure. 
In application of differential activation energy approach in its purest form, calculations at B3LYP/6$31 \mathrm{G}$ (d) level predicted outward openings of 3- $\mathrm{CF}_{3^{-}}, 3-\mathrm{CF}_{2} \mathrm{H}$ - and 3- $\mathrm{CH}_{2} \mathrm{~F}-\mathrm{cyclobutenes}$ favored over the corresponding inward openings by $2.3,0.3$ and $2.0 \mathrm{kcal} / \mathrm{mol}$, respectively. ${ }^{5}$ Activation energies calculated at M06-2X/6-311+G(2d,p) level by Barquera-Lozada, however, favored inward opening of 3- $\mathrm{CF}_{2} \mathrm{H}$-cyclobutene by $1.5 \mathrm{kcal} / \mathrm{mol} .{ }^{6}$ Dolbier and co-workers have experimentally discovered $3-\mathrm{CF}_{3}$ cyclobutene to open predominantly outward. ${ }^{7}$ The relative concentration of the inward product was found to significantly rise on raising the reaction temperature. For instance, the outward:inward ratio was discovered changed from $43.5: 1$ at $56.5^{\circ} \mathrm{C}$ to $13.2: 1$ at $188.5^{\circ} \mathrm{C}$ while the outward product was more stable than inward product with standard enthalpy difference of $2.5 \pm 0.4 \mathrm{kcal} / \mathrm{mol}$. The transformation of outward to inward product on rise in reaction temperature requires explanation because it possibly cannot be due to double bond isomerization for the requirement of generally high activation energy.

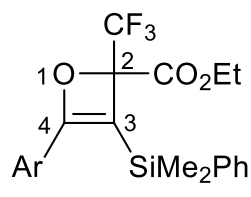

11

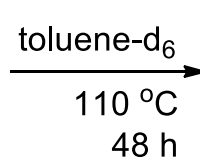

$48 \mathrm{~h}$

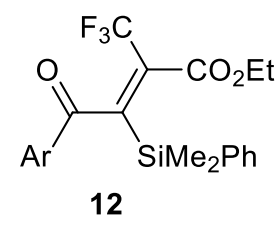

12

In 2011, Mikami studied the ring opening of 2- $\mathrm{CO}_{2} \mathrm{Et}-2-\mathrm{CF}_{3}-3$-dimethylphenylsilyl-4-aryloxetene 11 under thermal conditions (toluene- $\mathrm{d}_{6}, 110{ }^{\circ} \mathrm{C}, 48 \mathrm{~h}$ ) and observed its quantitative transformation to 12 with exclusive inward rotation of $\mathrm{CF}_{3} .{ }^{8} \mathrm{He}$ also observed predominance of inward rotation of $\mathrm{CF}_{3}$ on ring opening of the closely related 2- $\mathrm{CO}_{2} \mathrm{Et}-2-\mathrm{CF}_{3}-3-$ methyl-4-phenyloxetene by a margin of 81:19 at $70{ }^{\circ} \mathrm{C}$ and 77:23 at $100{ }^{\circ} \mathrm{C} .{ }^{9}$ The rise in concentration of the outward product on rise in reaction temperature must be noted. The results were explained by $\sigma_{\mathrm{C}-\mathrm{o}} \rightarrow \sigma_{\mathrm{C}-\mathrm{F}} *$ type NBO interaction that was larger in the TS for inward rotation of $\mathrm{CF}_{3}$ than outward rotation. Going by the original differential activation energy approach, $\mathrm{CF}_{3}$ group appears more electron-deficient than $\mathrm{CO}_{2} \mathrm{Et}$. It will be interesting to explore 2- $\mathrm{CF}_{3}$-oxetene alone to assess the otherwise unperturbed electronic effects of $\mathrm{CF}_{3}$ in regard to differential activation barrier and also NBO interactions.

In 2015, Houk and Mikami concluded from M06-2X/6-31+G(d,p) level calculations that the torquoselectivies of a series of mono-, di-, and trifluoromethylcyclobutenes and also oxetenes resulted from the interplay of favorable orbital interactions and closed-shell repulsions. ${ }^{10}$ The authors articulated that when the substituent rotated inward, there was a favorable interaction between the breaking $\sigma_{\mathrm{C}-\mathrm{o}}$ bond and $\sigma^{*}{ }_{\mathrm{C}-\mathrm{F}}$ of the fluoromethyl group in fluoromethyloxetenes. Also, the preference for inward rotation of a fluoromethyl group decreased because the closed-shell repulsion $n_{\mathrm{F}}-\sigma_{\mathrm{C}-\mathrm{O}}$ competed with $\sigma_{\mathrm{c}-\mathrm{O}} \rightarrow \sigma_{\mathrm{C}-\mathrm{F}} *$ interaction. The closed-shell repulsion arose when the distance between 
oxygen and fluorine was less than the sum of their van der Waals radii. An attempt to first amalgamate the differential activation barrier with NBO interaction to lend additional support to the former and then turning completely to NBO interaction alone is apparent.

Like the interaction $\sigma_{\mathrm{C}-\mathrm{O}} \rightarrow \sigma_{\mathrm{C}-\mathrm{F}} *$ in oxetenes, the interaction $\sigma_{\mathrm{C}-\mathrm{C}} \rightarrow \sigma_{\mathrm{C}-\mathrm{F}} *$ may also be expected in the openings of 3-fluoroalkyl-substituted cyclobutenes such as $3-\mathrm{CF}_{3^{-}}, 3-\mathrm{CHF}_{2^{-}}$and $3-\mathrm{CH}_{2} \mathrm{~F}-\mathrm{cyclobutenes}$. An investigation into this and also whether or not the findings differed from those for the corresponding oxetenes was, therefore, felt necessary. It also provides an opportunity to study, for the first time, the effects of conformational changes in $\mathrm{CHF}_{2}$ and $\mathrm{CH}_{2} \mathrm{~F}$ relative to the breaking ring bond. The orbital interaction is the greatest when the two bonds are antiperiplanar. ${ }^{11}$ The conformational effect of a substituent on torquoselectivity has not been investigated prior to this report.

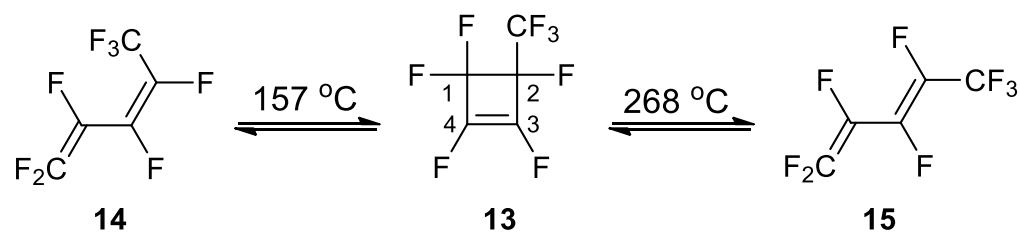

In 1986, Dolbier reported that perfluoro-3-methylcyclobutene 13 furnished only 14, the product of inward rotation of $\mathrm{CF}_{3}$, when the reaction was conducted at $157^{\circ} \mathrm{C}$. However, the product profile changed to exclusively 15 , the product of outward rotation of $\mathrm{CF}_{3}$, on conducting the reaction at 268 ${ }^{\circ} \mathrm{C} .{ }^{12}$ The switch over from (Z)-14 at lower temperature to $(E)-\mathbf{1 4}$ at higher temperature requires an explanation.

Computational Methodology: We have carried out quantum chemical calculations at MP2/cc-pVTZ level of theory using Gaussian $09^{13}$ to elucidate electronic controls on the torquoselectivities of 3fluoromethylcyclobutenes, 2-fluoromethyloxetenes and perfluoro-3-methylcyclobutene. Optimized structures were verified as minima or first order saddle points by harmonic vibrational frequency analyses. All the energies reported are Gibbs' Free Energies (Sum of electronic and thermal Free Energies). See the Supporting Information (SI) for the geometrical coordinates of the ground and transition state structures.

\section{Results and Discussion}

The activation energies of ring openings in $3-\mathrm{CF}_{3}-, 3-\mathrm{CF}_{2} \mathrm{H}$ - and $3-\mathrm{CH}_{2} \mathrm{~F}-\mathrm{cyclobuetenes}$ are collected in Table 1. For the substituents $\mathrm{CF}_{2} \mathrm{H}$ and $\mathrm{CH}_{2} \mathrm{~F}$, three different conformers were considered. The torsion angle of $\sigma_{C-H}$ bond in $\mathrm{CF}_{2} \mathrm{H}$ with $\sigma_{\mathrm{C3}-\mathrm{C} 4}$ bond of cyclobutene was varied to have three distinct conformers. Likewise, the torsion angle of $\sigma_{\mathrm{C}-\mathrm{F}}$ bond in $\mathrm{CH}_{2} \mathrm{~F}$ with $\sigma_{\mathrm{C3}-\mathrm{C} 4}$ bond of cyclobutene was varied. This exercise was taken to study the conformational effects on torquoselectivity. Some of the 
higher lying conformers are likely to be closer to the transition state structure and, hence, react faster than lower lying conformers. Further, since the NBO interactions in TS structures for different conformers are expected to be different in reference to stereoelectronic effects ${ }^{11}$, the torquoselectivity may alter completely or, in the least, the level may be affected.

Table 1. Gibbs free energies of activation $\left(\Delta G^{\ddagger}\right)$, kcal/mol, obtained at $298.15 \mathrm{~K}$ and 1 atm pressure for ring openings of 3-fluoromethylcyclobutenes as compared to 3-methylcyclobutene. The enthalpy changes $\left(\Delta G_{\text {product }}\right.$ - $\Delta G_{\text {reactant) }}$ are given in parentheses. $\Delta \Delta G^{\ddagger}=\Delta G^{\ddagger}$ outward $-\Delta G^{\ddagger}{ }_{\text {inward }}$

\begin{tabular}{|c|c|c|c|c|}
\hline Entry & Substituent & $\Delta \boldsymbol{G}_{\text {outward }}^{\ddagger}$ & $\Delta \boldsymbol{G}_{\text {inward }}^{\ddagger}$ & $\Delta \Delta \mathbf{G}^{\ddagger}$ \\
\hline 1 & $\mathrm{CF}_{3}$ & $33.2(-5.6)$ & $36.3(-1.8)$ & -3.1 \\
\hline 2 & $\mathrm{CHF}_{2}{ }^{\mathrm{a}}$ & $32.8(-5.4)$ & $33.2(-5.0)$ & -0.4 \\
\hline 3 & $\mathrm{CHF}_{\mathbf{2}}{ }^{\mathrm{b}}$ & $32.9(-6.2)$ & $36.1(-2.8)$ & -3.2 \\
\hline 4 & $\mathrm{CHF}_{2}{ }^{\mathrm{c}}$ & $31.9(-6.3)$ & $35.4(-2.0)$ & -3.5 \\
\hline 5 & $\mathrm{CH}_{2} \mathrm{~F}^{\mathrm{d}}$ & $31.4(-7.1)$ & $34.5(-5.7)$ & -3.1 \\
\hline 6 & $\mathrm{CH}_{2} \mathrm{~F}^{\mathrm{e}}$ & $31.3(-7.2)$ & $32.9(-6.3)$ & -1.6 \\
\hline 7 & $\mathbf{C H}_{2} \mathbf{F}^{f}$ & $30.6(-7.6)$ & $36.5(-3.5)$ & -5.9 \\
\hline
\end{tabular}

${ }^{a}$ Torsion angle $\mathrm{C} 4-\mathrm{C} 3-\mathrm{C}-\mathrm{H}=-47.0 .{ }^{\mathrm{b}}$ Torsion angle $\mathrm{C} 4-\mathrm{C} 3-\mathrm{C}-\mathrm{H}=70.7 .{ }^{\mathrm{c}}$ Torsion angle $\mathrm{C} 4-\mathrm{C} 3-\mathrm{C}-\mathrm{H}=-169.0$.

${ }^{\mathrm{d}}$ Torsion angle $\mathrm{C} 4-\mathrm{C} 3-\mathrm{C}-\mathrm{F}=72.6 .{ }^{\mathrm{e}}$ Torsion angle $\mathrm{C} 4-\mathrm{C} 3-\mathrm{C}-\mathrm{F}=-167.6 .{ }^{\mathrm{f}}$ Torsion angle $\mathrm{C} 4-\mathrm{C} 3-\mathrm{C}-\mathrm{F}=-49.4$

A bird's eye view of the activation energy data demonstrates that all the three substrates must open predominantly outwards. However, two entries need special mention. First, the most stable of the three conformers at Entry 2 shows the lowest level of selectivity with approximately 2:1 kinetic distribution of the products in favor of outward opening. The other two conformers must exclusively form the outward product for $>3.0 \mathrm{kcal} / \mathrm{mol}$ differential activation energies. Among conformers of the substrate bearing $\mathrm{CH}_{2} \mathrm{~F}$ substituent, all but the conformer at Entry 6 are expected to exclusively open outwards. The conformer at Entry 6 , which has $\sigma_{\mathrm{C3}-\mathrm{C4}}$ and $\sigma_{\mathrm{C}-\mathrm{F}}$ nearly antiperiplanar, is comparatively less selective as it can generate close to $10 \%$ of the inward product also.

Table 2. NBO interactions $(\mathrm{kcal} / \mathrm{mol})$ in the TSs for ring opening of 3-fluoromethycyclobutenes. The values in the parentheses are for inward opening TSs.

\begin{tabular}{lllll}
\hline Substrate & $\pi_{\mathrm{C} 1 \mathrm{C} 2} \rightarrow \sigma^{*}{ }_{\mathrm{C} 3 \mathrm{C} 4}$ & $\sigma_{\mathrm{C} 3 \mathrm{C} 4} \rightarrow \pi^{*}{ }_{\mathrm{C} 1 \mathrm{C2} 2}$ & $\sigma_{\mathrm{C} 3 \mathrm{C} 4} \rightarrow \sigma^{*}{ }_{\mathrm{C}-\mathrm{F} / \mathrm{H}}$ & $\sigma_{\mathrm{C}-\mathrm{F} / \mathrm{H} \rightarrow \sigma^{*}{ }_{\mathrm{C} 344}}$ \\
$\mathrm{CF}_{3}$ & $64(71)$ & $78(84)$ & $11(21)$ & $1.9(1.7)$ \\
$\mathrm{CHF}_{2}{ }^{\mathrm{a}}$ & $62(64)$ & $81(83)$ & $9(25)$ & $6.4(2.8)$ \\
$\mathrm{CHF}_{2}{ }^{\mathrm{b}}$ & $63(73)$ & $77(84)$ & $10(18)$ & $2.5(2.1)$ \\
$\mathrm{CHF}_{2}{ }^{\mathrm{c}}$ & $61(69)$ & $81(85)$ & $9(16)$ & $6.4(4.7)$ \\
$\mathrm{CH}_{2} \mathrm{~F}^{\mathrm{d}}$ & $55(62)$ & $78(85)$ & $7(19)$ & $9.5(4.0)$
\end{tabular}



$\mathrm{CH}_{2} \mathrm{~F}^{\mathrm{e}}$
$55(64)$
$78(81)$
$7(23)$
$\mathrm{CH}_{2} \mathbf{F}^{\mathrm{f}}$
$61(68)$
$80(86)$
7 (12)
$10(7.3)$
${ }^{\mathrm{a}}$ Torsion angle $\mathrm{C} 4-\mathrm{C} 3-\mathrm{C}-\mathrm{H}=-47.0 .{ }^{\mathrm{b}}$ Torsion angle $\mathrm{C} 4-\mathrm{C} 3-\mathrm{C}-\mathrm{H}=70.7 .{ }^{\mathrm{C}}$ Torsion angle $\mathrm{C} 4-\mathrm{C} 3-\mathrm{C}-\mathrm{H}=-169.0$.
${ }^{\mathrm{d}}$ Torsion angle $\mathrm{C} 4-\mathrm{C} 3-\mathrm{C}-\mathrm{F}=72.6$. ${ }^{\mathrm{e}}$ Torsion angle $\mathrm{C} 4-\mathrm{C} 3-\mathrm{C}-\mathrm{F}=-167.6 .{ }^{\mathrm{f}}$ Torsion angle $\mathrm{C} 4-\mathrm{C} 3-\mathrm{C}-\mathrm{F}=-49.4$.

We now switch to looking at the NBO interactions collected in Table 2. The interactions $\sigma_{\mathrm{c} 3 \mathrm{C} 4} \rightarrow \sigma^{*} \mathrm{c}$ $\mathrm{F} / \mathrm{H}$ and $\sigma_{\mathrm{C}-\mathrm{F} / \mathrm{H}} \rightarrow \sigma^{*}{ }_{\mathrm{C3C4}}$ are to be taken together because both weaken $\sigma_{\mathrm{C3} C 4}$ bond. The $\sigma_{\mathrm{C}-\mathrm{F} / \mathrm{H}}$ refers to all the $\sigma_{C-H}$ and $\sigma_{C-F}$ bonds in the substituent group. On account of significantly higher interaction in the inward mode of opening compared to interactions in the corresponding outward opening, all the three substrates are predicted to cause inward opening, which clearly contradicts the prediction made by the differential activation energy approach. The difference of interactions in the inward and outward openings of the least stable conformer at the last entry is the least $(2.3 \mathrm{kcal} / \mathrm{mol})$ and, hence, the level of torquoselectivity may be compromised.

Suitable orbital interaction is more important than steric interaction, so much so that conformers facing severest of steric interactions are known to react in exclusive preference to the all relaxed (the most stable) conformer. ${ }^{14}$ We subscribe to NBO interaction argument for prediction of torquoselectivity. We present the results herein.

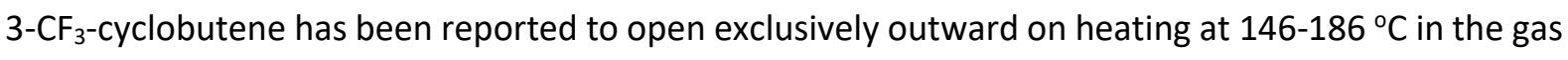
phase at 3-4 mm pressure in a sealed tube. The experimental results of ring openings of 3-CHF ${ }_{2}$ and 3- $\mathrm{CH}_{2} \mathrm{~F}$-cyclobutenes are not reported in the literature. Both outward and inward openings of 3- $\mathrm{CHF}_{2}-$ and $3-\mathrm{CH}_{2} \mathrm{~F}$-cyclobutenes are estimated to be sufficiently exergonic to discourage equilibration through reversal under mild conditions. In contrast, the inward opening of 3-CF 3 -Cyclobutene is only $1.8 \mathrm{kcal} / \mathrm{mol}$ exergonic in comparison to $5.6 \mathrm{kcal} / \mathrm{mol}$ for outward opening. This translates into 38.1 and $38.8 \mathrm{kcal} / \mathrm{mol}$ as activation energies for the ring closing reverse reactions of inward and outward products, respectively. Since the barrier for ring closing reaction of the inward opened product is only $1.8 \mathrm{kcal} / \mathrm{mol}$ higher than the corresponding ring opening reaction, it is likely that the two processes compete under the high energy conditions of the reaction while the more stable outward product accumulates to predominate. The profiles of the reaction of $3-\mathrm{CF}_{3}-\mathrm{Cyclobutene}$ are given in Figure 1 . 


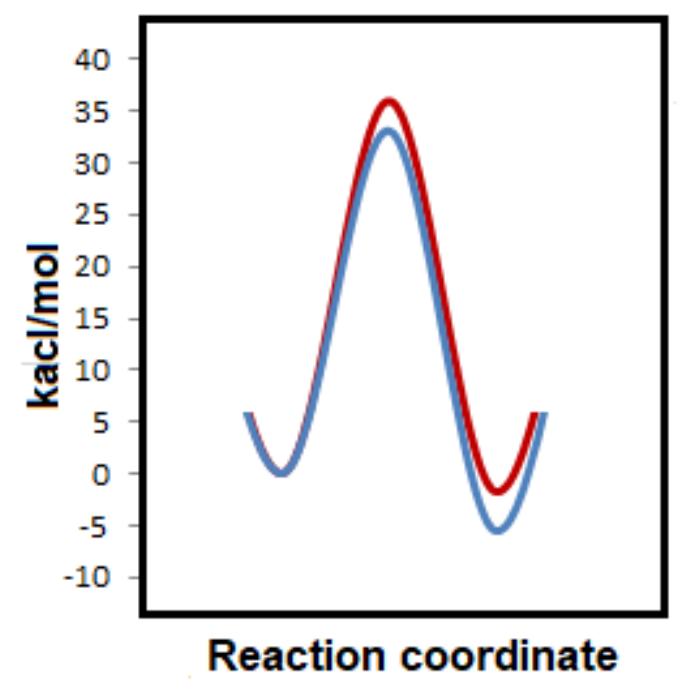

Figure 1. Reaction profile for inward (solid red line) and outward (solid blue line) ring openings in $3-\mathrm{CF}_{3}$ cyclobutene

The activation energies and enthalpy changes for opening of 2-fluoromethyloxetenes are collected in Table 3. All the reactions are highly exergonic and, hence, equilibration by reaction reversal is unlikely. Since the activation energy for outward opening is significantly lower than inward opening, exclusive outward opening is predicted. The conformer at Entry 2, however, deserves special comment. This conformer is the most stable among the three conformers. The differential activation energy is only $0.7 \mathrm{kcal} / \mathrm{mol}$ and, hence, it will be expected to generate $20-25 \%$ of the inward product also. The reaction profiles for outward and inward openings of 3-CF - -cyclobutene are given in Figure 2.

Table 3. Gibbs free energies of activation $\left(\Delta G^{\ddagger}\right)$, $\mathrm{kcal} / \mathrm{mol}$, obtained at $298 \mathrm{~K}$ and 1 atm pressure for the ring openings of 2-fluoromethyloxetenes. The enthalpy changes ( $\Delta G_{\text {product }}-\Delta G_{\text {reactant }}$ ) are given in the parentheses. $\Delta \Delta G^{\ddagger}=\Delta G^{\ddagger}$ outward $-\Delta G^{\ddagger}{ }_{\text {inward }}$

\begin{tabular}{lllll}
\hline Entry & Substituent & $\Delta \boldsymbol{G}^{\ddagger}{ }_{\text {outward }}$ & $\Delta \boldsymbol{G}^{\ddagger}{ }_{\text {inward }}$ & $\Delta \Delta \mathbf{G}^{\mathbf{q}}$ \\
\hline 1 & $\mathbf{C F}_{3}$ & $28.0(-25.7)$ & $30.8(-20.1)$ & -2.8 \\
2 & $\mathbf{C H F}_{2}{ }^{a}$ & $28.5(-24.3)$ & $29.2(-23.1)$ & -0.7 \\
3 & $\mathbf{C H F}_{2}{ }^{b}$ & $27.2(-25.5)$ & $29.9(-24.3)$ & -2.7 \\
4 & $\mathbf{C H F}_{2}{ }^{\mathrm{c}}$ & $26.5(-26.6)$ & $30.8(-19.5)$ & -4.3 \\
5 & $\mathbf{C H}_{2} \mathbf{F}^{\mathrm{d}}$ & $24.7(-24.3)$ & $31.0(-24.9)$ & -6.3 \\
6 & $\mathbf{C H}_{2} \mathbf{F}^{\mathrm{e}}$ & $24.2(-24.8)$ & $28.5(-25.5)$ & -4.3 \\
7 & $\mathbf{C H}_{2} \mathbf{F}^{\mathrm{f}}$ & $24.2(-26.7)$ & $30.7(-26.0)$ & -6.5
\end{tabular}

${ }^{a}$ Torsion angle $\mathrm{O} 1-\mathrm{C} 2-\mathrm{C}-\mathrm{H}=-49.1 .{ }^{\mathrm{b}}$ Torsion angle $\mathrm{O} 1-\mathrm{C} 2-\mathrm{C}-\mathrm{H}=60.6 .{ }^{\mathrm{c}}$ Torsion angle $\mathrm{O} 1-\mathrm{C} 2-\mathrm{C}-\mathrm{H}=-172.6$.

${ }^{\mathrm{d}}$ Torsion angle $\mathrm{O} 1-\mathrm{C} 2-\mathrm{C}-\mathrm{F}=74.6 .{ }^{\mathrm{e}}$ Torsion angle $\mathrm{O} 1-\mathrm{C} 2-\mathrm{C}-\mathrm{F}=-174.7 .{ }^{\mathrm{f}}$ Torsion angle $\mathrm{O} 1-\mathrm{C} 2-\mathrm{C}-\mathrm{F}=-61.9$. 


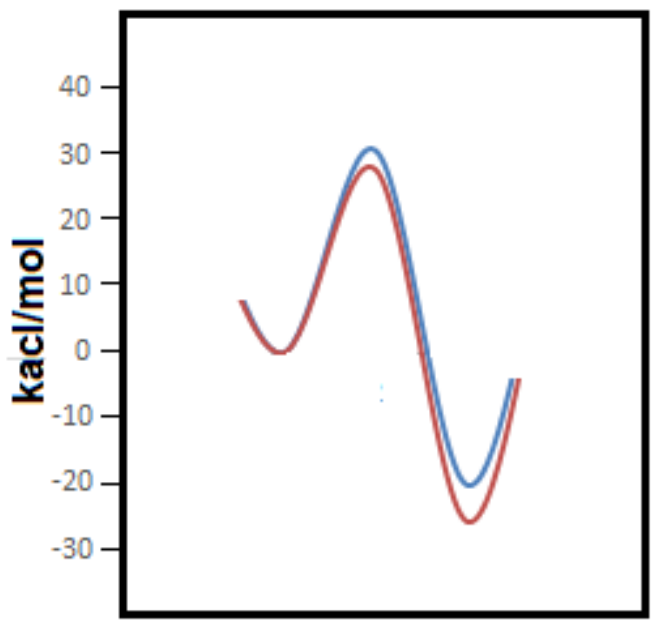

Reaction coordinate

Figure 2. Reaction profile for inward (solid blue line) and outward (solid red line) ring openings in 2trifluoromethyloxetene

In contrast, NBO interactions $\sigma_{\mathrm{C}-\mathrm{O}} \rightarrow \sigma^{*}{ }_{\mathrm{C}-\mathrm{F}}$ and $\sigma_{\mathrm{C}-\mathrm{F}} \rightarrow \sigma^{*}{ }_{\mathrm{C}-\mathrm{O}}$ support inward rotation of $\mathrm{CF}_{3}$ group because their sum is $>7.0 \mathrm{kcal} / \mathrm{mol}$ larger in the TS structure for inward over outward rotation. Though all the conformers of $\mathrm{CHF}_{2}$ are favored for inward rotation, the differential interaction decreases from 5.3 to 4.9 to $2.0 \mathrm{kcal} / \mathrm{mol}$ as one descends the Table. This could be taken for overall reduced torquoselectivity. The story with $\mathrm{CH}_{2} \mathrm{~F}$ substituent is different. The differential interaction is small, but in support of outward opening for the first two conformers and a mixture for the last one. Overall, 3$\mathrm{CH}_{2} \mathrm{~F}$-cyclobutene is predicted for largely outward opening, which is the same as that predicted by differential activation energy. The NBO interactions are collected in Table 4.

Table 4. NBO interactions $(\mathrm{kcal} / \mathrm{mol})$ in the TSs for the ring opening of 2-fluoromethyloxetenes. The values in the parentheses represent interactions in the inward opening TSs.

\begin{tabular}{lllll}
\hline Substrate & $\pi_{\mathrm{C} 3 \mathrm{C} 4 \rightarrow \sigma_{\mathrm{C}-\mathrm{O}}}$ & $\sigma_{\mathrm{C}-\mathrm{O} \rightarrow \pi^{*}{ }_{\mathrm{C} 3 \mathrm{C} 4}}$ & $\sigma_{\mathrm{C}-\mathrm{O} \rightarrow \sigma_{\mathrm{C}-\mathrm{F} / \mathrm{H}}}$ & $\sigma_{\mathrm{C}-\mathrm{f} / \mathrm{H} \rightarrow \sigma^{*}{ }_{\mathrm{C}-\mathrm{O}}}$ \\
$\mathrm{CF}_{3}$ & $72(80)$ & $53(61)$ & $2.4(10)$ & $3.0(2.6)$ \\
$\mathrm{CHF}_{2}{ }^{a}$ & $70(76)$ & $54(63)$ & $1.8(12)$ & $7.9(3.0)$ \\
$\mathrm{CHF}_{2}{ }^{\mathrm{b}}$ & $70(79)$ & $54(60)$ & $1.8(10)$ & $7.9(4.6)$ \\
$\mathrm{CHF}_{2}{ }^{\mathrm{c}}$ & $74(78)$ & $57(63)$ & $1.8(8.0)$ & $12.4(8.2)$ \\
$\mathrm{CH}_{2} \mathrm{~F}^{\mathrm{d}}$ & $66(76)$ & $62(72)$ & $1.5(7.7)$ & $18(10)$ \\
$\mathrm{CH}_{2} \mathrm{~F}^{\mathrm{e}}$ & $66(71)$ & $62(59)$ & $1.5(12)$ & $18(4.9)$ \\
$\mathrm{CH}_{2} \mathrm{~F}^{\mathrm{f}}$ & $68(73)$ & $56(64)$ & $1.5(6.6)$ & $19(14)$
\end{tabular}

${ }^{a}$ Torsion angle $\mathrm{O} 1-\mathrm{C} 2-\mathrm{C}-\mathrm{H}=-49.1 .{ }^{\mathrm{b}}$ Torsion angle $\mathrm{O} 1-\mathrm{C} 2-\mathrm{C}-\mathrm{H}=60.6 .{ }^{\mathrm{c}}$ Torsion angle $\mathrm{O} 1-\mathrm{C} 2-\mathrm{C}-\mathrm{H}=-172.6$.

${ }^{\mathrm{d}}$ Torsion angle O1-C2-C-F = 74.6. ${ }^{\mathrm{e}}$ Torsion angle $\mathrm{O} 1-\mathrm{C} 2-\mathrm{C}-\mathrm{F}=-174.7 .{ }^{\mathrm{f}}$ Torsion angle O1-C2-C-F = -61.9. 
Finally, we return to perfluoro-3-methylcyclobutene, which is reported to furnish only the (Z)-product from inward rotation of $\mathrm{CF}_{3}$ on conducting the reaction at $157^{\circ} \mathrm{C}$ and $(E)$-product from outward rotation of $\mathrm{CF}_{3}$ when the reaction was conducted at $268^{\circ} \mathrm{C}^{12}$ The activation energies for ring openings entailing inward and outward rotations of $\mathrm{CF}_{3}$ are, respectively, 38.9 and $48.1 \mathrm{kcal} / \mathrm{mol}$. Thus, the inward rotation is favored over outward rotation by $9.2 \mathrm{kcal} / \mathrm{mol}$. Both the reactions are endergonic, the enthalpy change being 7.5 and $7.9 \mathrm{kcal} / \mathrm{mol}$, respectively, and hence reversible. The activation energies of ring closing reactions, therefore, are 31.4 and $40.3 \mathrm{kcal} / \mathrm{mol}$, respectively. The activation energies are collected in Table 5.

Table 5. Energies of activation $\left(\Delta G^{\ddagger}\right), \mathrm{kcal} / \mathrm{mol}$, obtained at $298.15 \mathrm{~K}$ and $1 \mathrm{~atm}$ pressure for ring openings of perfluoro-3-methylcyclobutene 13 . The enthalpy change ( $\left.\Delta G_{\text {product }}-\Delta G_{\text {reactant }}\right)$ is given in parentheses. $\Delta \Delta G^{\ddagger}=$ $\Delta G^{\ddagger}{ }_{\text {outward }}-\Delta G^{\ddagger}$ inward

\begin{tabular}{llll}
\hline Substrate & $\Delta \boldsymbol{G}^{\ddagger}$ outward & $\Delta \boldsymbol{G}^{\ddagger}{ }_{\text {inward }}$ & $\Delta \Delta \mathbf{G}^{\ddagger}$ \\
\hline 13 & $48.1(7.5)$ & $38.9(7.9)$ & 9.2
\end{tabular}

Table 6. NBO interactions $(\mathrm{kcal} / \mathrm{mol})$ in the TSs for ring opening of perfluoro-3-methylcyclobutene 13. The values in the parentheses are for inward opening TS structures

\begin{tabular}{lllll}
\hline$\pi_{\mathrm{C} 1 \mathrm{C} 2} \rightarrow \sigma^{*}{ }_{\mathrm{C} 3 \mathrm{C} 4}$ & $\pi_{\mathrm{C} 1 \mathrm{C} 4} \rightarrow \pi^{*}{ }_{\mathrm{C} 2 \mathrm{C3}}$ & $\pi_{\mathrm{C} 2 \mathrm{C} 3} \rightarrow \pi^{*}{ }_{\mathrm{C} 1 \mathrm{C} 4}$ & $\sigma_{\mathrm{C} 3 \mathrm{C} 4} \rightarrow \sigma^{*}{ }_{\mathrm{C}-\mathrm{F}}$ & $\mathrm{Ip}_{\mathrm{F}} \rightarrow \pi^{*}{ }_{\mathrm{C} 1 \mathrm{C} 4 / \mathrm{C} 2 \mathrm{C3}}$ \\
$0(0)$ & $65(62)$ & $60(60)$ & $0(0)^{\mathrm{a}}$ & $76(77)^{\mathrm{b}}$
\end{tabular}

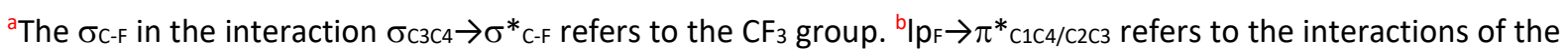
lone pairs of electrons of the fluorine atoms directly attached to C3 and C4.

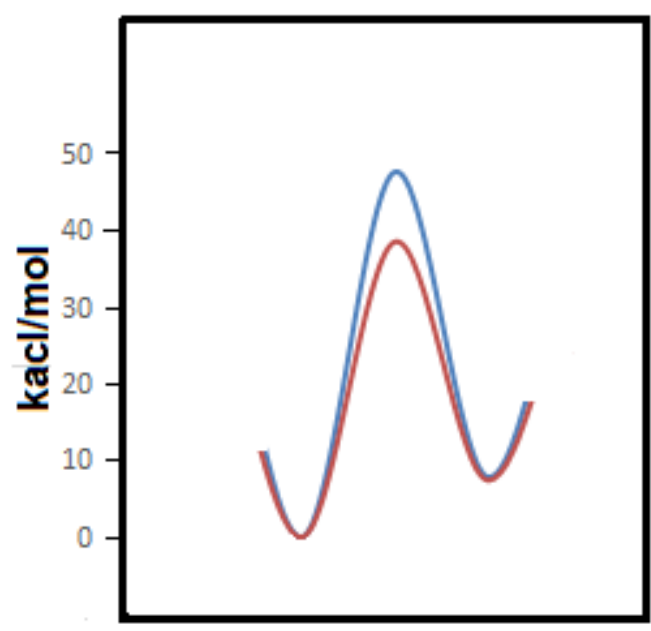

Reaction coordinate

Figure 3. Reaction profile for inward (solid red line) and outward (solid blue line) ring openings in perfluoro-3methylcyclobutene 
At the lower end of temperature $\left(157^{\circ} \mathrm{C}\right)$, only lower energy inward opening leading to Z-olefin and the associated ring closing reactions predominate, and we observe only the (Z)-olefin 14 . At the higher end of reaction temperature $\left(268{ }^{\circ} \mathrm{C}\right)$, outward ring opening pathway requiring higher activation energy also becomes active and the consequent $(E)$-product $\mathbf{1 5}$ predominates for its relatively lower reversibility due to larger thermodynamic stability.

The relevant NBO interactions are collected in Table 6 . The absence of $\pi_{\mathrm{C} 1 \mathrm{C2} 2} \rightarrow \sigma^{*}{ }_{\mathrm{c3c}}$ interaction, and presence of $\pi_{\mathrm{C} 1 \mathrm{C}_{4}} \rightarrow \pi^{*}{ }_{\mathrm{C} 2 \mathrm{C} 3}$ and $\pi_{\mathrm{C} 2 \mathrm{C} 3} \rightarrow \pi^{*}{ }_{\mathrm{C} 1 \mathrm{C} 4}$ interactions clearly demonstrate that the TS structure is heavily advanced and product-like in both modes of ring opening. The $\sigma_{c 3 c 4}$ bond is completely broken and, hence, its interaction with $\sigma^{*}{ }_{C-F}$ in $\mathrm{CF}_{3}$ group is absent. $\mathrm{F}$ atoms directly bonded to the ring play a key role and the interactions of their lone pairs with the largely developed $\pi$ bonds between $\mathrm{C} 1$ and $\mathrm{C} 4$, and $\mathrm{C} 2$ and $\mathrm{C} 3$ control the torquoselectivity. This differential interaction, however, is marginal and in favor of inward rotation by only $1.0 \mathrm{kcal} / \mathrm{mol}$. The profiles for ring opening reactions are shown in Figure 3.

Conclusions. The torquoselectivity of ring opening of substituted cyclobutenes and oxetenes is a consequence of NBO interactions of the breaking ring bond with substituent orbitals. The ring opening (outward or inward) that has larger interaction constitutes the preferred pathway. The experimental torquoselectivity, if otherwise, is a likely consequence of secondary reactions, specifically equilibration by reaction reversal, while honouring the relative enthalpic stabilities of ring opened products.

The conformational profile of substituent relative to the cleaving bond also impacts the torquoselectivity and, hence, it must be taken into consideration in any comprehensive treatment of the subject. ${ }^{15}$ Conformational issues arise because the effective NBO interactions are largely antiperiplanar interactions and, hence, the relative orientation of the cleaving ring bond with the substituent bond is important.

\section{ASSOCIATED CONTENT}

\section{Supporting Information}

Supporting Information (SI) available: Cartesian coordinates of the optimized substrates and TS structures, Gibbs' free energies of the ground and TS structures, Imaginary Frequencies of the TS structures (34 pages)

\section{ORCID}

Veejendra K. Yadav: 0000-0001-8294-0677 


\section{ACKNOWLEDGEMENTS}

The author acknowledges allocation of time on HPC series of supercomputers by the Computer Centre, Indian Institute of Technology Kanpur, and Dr. Dasari L. V. K. Prasad for fruitful discussions.

\section{REFERENCES}

1. R. B. Woodward, R. Hoffmann, Stereochemistry of Electrocyclic Reactions, J. Am. Chem. Soc. 1965, 87, 395-397.

2. (a) W. Kirmse, N. G. Rondan, K. N Houk, Stereoselective substituent effects on conrotatory electrocyclic reactions of cyclobutenes, J. Am. Chem. Soc. 1984, 106, 7989-7991. (b) N. G. Rondan, K. N. Houk, Theory of stereoselection in conrotatory electrocyclic reactions of substituted cyclobutenes, J. Am. Chem. Soc. 1985, 107, 2099-2111. (c) K. Rudolf, D. C. Spellmeyer, K. N. Houk, Prediction and experimental verification of the stereoselective electrocyclization of 3-formylcyclobutene, J. Org. Chem. 1987, 52, 3708-3710. (d) K. N. Houk, D. C. Spellmeyer, C. W. Jefford, C. G. Rimbault, Y. Wang, R. D. Miller, Electronic control of the stereoselectivities of electrocyclic reactions of cyclobutenes against incredible steric odds, J. Org. Chem. 1988, 53, 2125-2127. (e) C. W. Jefford, G. Bernardinelli, Y. Wang, D. C. Spellmeyer, A. Buda, K. N. Houk, Torquoselectivity in the electrocyclic conversion of benzocyclobutenes to o-xylylenes, J. Am. Chem. Soc. 1992, 114, 1157-1165. (f) S. Niwayama, K. N. Houk, Lewis acid reversal of the torquoselectivity of the electrocyclic ring opening of 3-acetylcyclobutene, Tetrahedron Lett. 1993, 34, 1251-1254. (g) K. Nakamura, K. N. Houk, Substituent Effects on Torquoselectivity. Computational Investigations of the Thermal Ring Openings of Cyclobutenes Fused to Substituted Cyclohexenes, J. Org. Chem. 1995, 60, 686-691. (h) S. Niwayama, Y. Wang, K. N. Houk, The torquoselectivity of electrocyclic reactions of 3-donor-3-acceptor-substituted cyclobutenes, Tetrahedron Lett. 1995, 36, 6201-6204. (i) S. Niwayama, A. K. Kallel, D. C. Spellmeyer, C. Sheu, K. N. Houk, Substituent Effects on Rates and Stereoselectivities of Conrotatory Electrocyclic Reactions of Cyclobutenes. A Theoretical Study, J. Org. Chem. 1996, 61, 2813-2825.

3. M. Murakami, T. Miyamoto, Y. Ito, A Silyl Substituent Can Dictate a Concerted Electrocyclic Pathway: Inward Torquoselectivity in the Ring Opening of 3-Silyl-1-cyclobutene, Angew. Chem., Int. Ed. 2001, 40, 189-190.

4. The frequency calculation for the TS structures could not be achieved at the MP2/cc-pVTZ level.

5. P. S. Lee, X. Zhang, K. N. Houk, Origins of Inward Torquoselectivity by Silyl Groups and Other $\sigma$-Acceptors in Electrocyclic Reactions of Cyclobutenes, J. Am. Chem. Soc. 2003, 125, 5072-5079.

6. J. E. Barquera-Lozada, Torquoselectivity in Cyclobutene Ring Openings and the Interatomic Interactions That Control Them, J. Phys. Chem. A 2016, 120, 8450-8460.

7. (a) W. R. Dolbier, Jr, T. A. Gray, J. J. Keaffaber, L. Celewicz, H. Koroniak, Kinetic and Thermodynamic Effects in the Thermal Electrocyclic Ring-Openings of 3-Fluorocyclobutene, 3,3-Difluorocyclobutene, and 3-(Trifluoromethyl)cyclobutene, J. Am. Chem. Soc. 1990, 112, 363-367. (b) W. R. Dolbier, Jr, H. Koroniak, K. N. Houk, C. Sheu, Electronic Control of Stereoselectivities of Electrocyclic Reactions of 
Cyclobutenes: A Triumph of Theory in the Prediction of Organic Reactions, Acc. Chem. Res., 1996, 29, 471-477.

8. K. Aikawa, Y. Hioki, N. Shimizu, K. Mikami, Catalytic Asymmetric Synthesis of Stable Oxetenes via Lewis Acid-Promoted [2 + 2] Cycloaddition, J. Am. Chem. Soc. 2011, 133, 20092-20095.

9. K. Aikawa, N. Shimizu, K. Honda, Y. Hioki, K. Mikami, Effect of the trifluoromethyl group on torquoselectivity in the $4 \pi$ ring-opening reaction of oxetenes: stereoselective synthesis of tetrasubstituted olefins, Chem. Sci. 2014, 5, 410-415.

10. K. Honda, S. A. Lopez, K. N. Houk, K. Mikami, Mono-, Di-, and Trifluoroalkyl Substituent Effects on the Torquoselectivities of Cyclobutene and Oxetene Electrocyclic Ring Openings, J. Org. Chem. 2015, 80, 11768-11772. The publication concludes, "The torquoselectivities are thus controlled by a competition of $\sigma_{\mathrm{CO}} \rightarrow \sigma_{\mathrm{CF}} *$ effect and unfavorable closed-shell repulsions. Our calculations suggest that 2difluoromethyloxetenes prefer inward rotation because the favorable $\sigma_{\mathrm{CO}} \rightarrow \sigma_{\mathrm{CF}} *$ orbital effect outweighs closed-shell repulsions in the transition state."

11. P. Deslongchamps, Stereoelectronic Effects in Organic Chemistry, Pergamon Press, 1983.

12. W. R. Dolbier, H. Koroniak, D. J. Burton, P. Heinze, The electrocyclic interconversion of perfluoro-3methylcyclubutene with Z- and E-perfluro-1,3-pentadiene, Tetrahedron Lett. 1986, 27, 4387-4390.

13. M. J. Frisch, G. W. Trucks, H. B. Schlegel, G. E. Scuseria, M. A. Robb, J. R. Cheeseman, G. Scalmani, V. Barone, B. Mennucci, G. A. Petersson, H. Nakatsuji, M. Caricato, X. Li, H. P. Hratchian, A. F. Izmaylov, J. Bloino, G. Zheng, J. L. Sonnenberg, M. Hada, M. Ehara, K. Toyota, R. Fukuda, J. Hasegawa, M. Ishida, T. Nakajima, Y. Honda, O. Kitao, H. Nakai, T. Vreven, J. A. Montgomery Jr., J. E. Peralta, F. Ogliaro, M. Bearpark, J. J. Heyd, E. Brothers, K. N. Kudin, V. N. Staroverov, T. Keith, R. Kobayashi, J. Normand, K. Raghavachari, A. Rendell, J. C. Burant, S. S. Iyengar, J. Tomasi, M. Cossi, N. Rega, J. M. Millam, M. Klene, J. E. Knox, J. B. Cross, V. Bakken, C. Adamo, J. Jaramillo, R. Gomperts, R. E. Stratmann, O. Yazyev, A. J. Austin, R. Cammi, C. Pomelli, J. W. Ochterski, R. L. Martin, K. Morokuma, V. G. Zakrzewski, G. A. Voth, P. Salvador, J. J. Dannenberg, S. Dapprich, A. D. Daniels, O. Farkas, J. B. Foresman, J. V. Ortiz, J. Cioslowski, D. J. Fox, Gaussian 09, revision C.01, Gaussian, Inc., Wallingford, CT 2009.

14. J. A. Berson, The overlap component of the stereoelectronic factor. Remote control of stereogenicity transfer through the anisotropic influence of a ring, Acc. Chem. Res. 1991, 24, 215-222.

15. For a brief mention of conformational effect arising from geminal ethyl versus methyl groups, see: $E$. A., Kallel, Y. Wang, D. C. Spellmeyer, K. N. Houk, Electrocyclic ring openings of dialkylcyclobutenes: anomalies explained, J. Am. Chem. Soc. 1990, 112, 6759-6763. The inward rotation of the ethyl group was considered to give rise to more favorable gauche interactions than the methyl group. 


\section{For Table of Contents}

The conformational profile of substituent relative to the cleaving bond impacts torquoselectivity. The ring opening (outward or inward) that has larger NBO interaction in the transition state structure constitutes the preferred pathway.

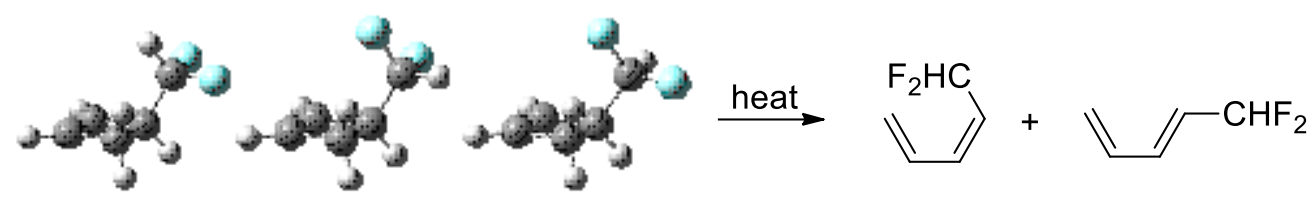

OR

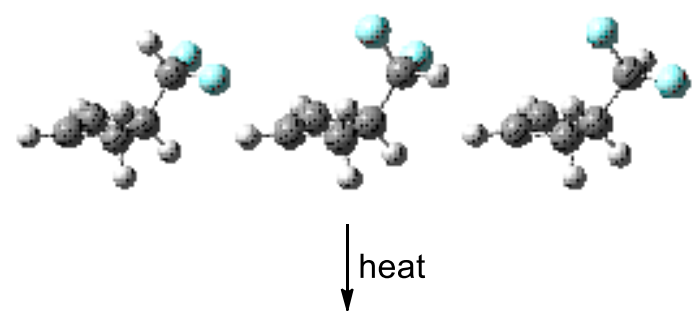

$\stackrel{\mathrm{F}_{2} \mathrm{HC}}{\Downarrow}+\Downarrow / \mathrm{CHF}^{-}$ 